\title{
Prospective comparison of the fluorescein-dilaurate test with the secretin-cholecystokinin test for pancreatic exocrine function
}

\author{
EJS BOYD, JGR CUMMING, A CUSCHIERI, RAB WOOD, KG WORMSLEY \\ From the Departments of Surgery and Therapeutics, University of Dundee, Dundee
}

SUMMARY In a prospective study of 60 patients undergoing investigation for possible exocrine pancreatic disease the fluorescein-dilaurate test was compared with the secretin-cholecystokinin (CCK) test. Forty one patients had a normal response to secretin-CCK, 14 patients had abnormal responses and in five patients the results were equivocal. Taking the secretin-CCK test as the diagnostic criterion, the fluorescein-dilaurate test had a sensitivity of $100 \%$ and a negative predictive value of $100 \%$. There was a $54 \%$ false-positive rate. The fluorescein-dilaurate test is easy to perform and is a useful screening test for pancreatic exocrine insufficiency.

The most sensitive test of pancreatic exocrine function is the secretin-CCK test. ${ }^{12}$ This test requires duodenal intubation, which may be unpleasant to patients, and must be performed by a skilled operator for the results to be valid. A further disadvantage is the high cost of the hormones used ( $£ 16.50$ per test). An inexpensive. tubeless pancreatic function test which was easy to perform and which could be used as a screening test for pancreatic exocrine insufficiency would be useful in reducing the number of patients requiring intubation. In this study we have prospectively compared the secretinCCK test with the fluorescein-dilaurate test, a simple oral test of pancreatic digestive capacity, in patients undergoing investigation for possible pancreatic disease.

\section{Patients and methods}

Sixty patients were studied ( 32 males 28 females, age range 14 to $75 \mathrm{yr}$ ). All were undergoing inpatient investigation for possible pancreatic disease. or for evaluation of pancreatic exocrine function after pancreatic resection. All patients had both a secretin-CCK test and a fluorescein-dilaurate test. Details of the individual patients together with the final diagnosis are shown in Tables 1-3.

SIECRETIN-CHOI.ICYSTOKININ TEST

Each test was performed after an overnight fast. The duodenum was intubated and pancreatic secretion was stimulated by a constant intravenous infusion of secretin ( 1 Clinical Unit/kg/h) and CCK ( I Ivy Dog Unit/kg/h).

Accepted for publication 12 May 1982
Duodenal contents, uncontaminated by gastric secretions, were collected in $3 \times 15$ min samples and the volumes noted. An aliquot was assayed for bicarbonate concentration. Patients were considered to have normal exocrine pancreatic function if the maximal bicarbonate response was greater than $20 \mathrm{mmol} / \mathrm{h}$, and to have? exocrine insufficiency if the response was less than 15 $\mathrm{mmol} / \mathrm{h}$. A bicarbonate response of $\geqslant 15 \leqslant 20 \mathrm{mmol} / \mathrm{h}$ was considered equivocal.

FIUORESCEIN DILAURATE TEST

Fluorescein dilaurate is apparently a specific substrate for pancreatic aryl esterase ${ }^{3}$ and is hydrolysed by this enzyme in the upper small intestine. Fluorescein is released, absorbed and excreted in the urine. The urinary output of fluorescein therefore gives an indication of pancreatic exocrine function. Tests were carried out according to the manufacturer's instructions (Temmler-Werke. Hamburg. FRG) which are contained in each test packet. On the test day the patient received two capsules, each containing $0.25 \mathrm{mmol}$ of fluorescein dilaurate, together with a light breakfast. Diuresis was encouraged by a liberal fluid intake and urine was collected for 10 hours after the ingestion of the capsules. A control study, in which the patient received a capsule containing $0.5 \mathrm{mmol}$ of unesterified fluorescein, was performed on a separate day under similar conditions. This is to detect and permit correction for any abnormalities of intestinal absorption. distribution, or renal excretion of fluorescein. At least one day was allowed to elapse between the test and the control days. Pancreatic enzyme supplements, vitamin B preparations (which absorb light at $492 \mathrm{~nm}$ ) and drugs affecting 
Table 1 Patients with normal response to secretin and CCK

\begin{tabular}{|c|c|c|c|c|c|}
\hline Case & Age (yr) & Sex & Diagnosis & $\begin{array}{l}\text { Maximal } \\
\text { bicarbonate output } \\
\text { (minol/h) }\end{array}$ & $\begin{array}{l}\text { Fluorescein excretion } \\
\text { \% control day }\end{array}$ \\
\hline 1 & 17 & $\mathbf{M}$ & Crohn's disease: intestinal resection & $32 \cdot 2$ & $71 \cdot 0$ \\
\hline 2 & 67 & $\mathrm{M}$ & Postgastrectomy syndrome & $40 \cdot \overline{7}$ & $35 \cdot 0$ \\
\hline 3 & 22 & $\mathbf{F}$ & Irritable bowel syndrome (pain) & $29 \cdot 0$ & $90 \cdot 3$ \\
\hline 4 & 17 & $\mathrm{M}$ & Crohn's disease & $34 \cdot 5$ & $83 \cdot 6$ \\
\hline 5 & 61 & $\mathbf{M}$ & Chronic active hepatitis & $26 \cdot 6$ & $79 \cdot 7$ \\
\hline 6 & 14 & $\mathbf{M}$ & Irritable bowel syndrome (pain) & $14 \cdot 0$ & $55 \cdot 7^{*}$ \\
\hline 7 & 27 & $\mathrm{~F}$ & Irritable bowel syndrome (pain) & $25 \cdot 2$ & $34 \cdot 6$ \\
\hline 8 & 29 & $\mathrm{~F}$ & Previous acute pancreatitis & $24 \cdot 7$ & $50 \cdot 2$ \\
\hline 9 & 59 & $\mathrm{~F}$ & Coeliac disease (inactive) & $25 \cdot 4$ & $46 \cdot \overline{7}$ \\
\hline 10 & 51 & $\mathbf{M}$ & Coeliac disease lymphoma & $21 \cdot 8$ & $57 \cdot 1$ \\
\hline 11 & 66 & $\mathrm{~F}$ & Coeliac disease (active) & $27 \cdot 7$ & $39 \cdot 1$ \\
\hline 12 & 73 & $\mathrm{~F}$ & No organic disease & $30 \cdot 7$ & $32 \cdot 4$ \\
\hline 13 & 71 & $\mathbf{M}$ & Chronic pancreatitis (biopsy positive) & $38 \cdot 5$ & $46 \cdot 8$ \\
\hline 14 & 41 & $\mathrm{~F}$ & Crohn's disease & $50 \cdot 9$ & $64 \cdot 1$ \\
\hline 15 & 71 & $\mathbf{M}$ & Previous acute pancreatitis & $24 \cdot 8$ & $65 \cdot 0$ \\
\hline 16 & 39 & $\mathrm{~F}$ & Cholelithiasis & $24 \cdot 4$ & $56 \cdot 7$ \\
\hline 17 & 43 & $\mathrm{M}$ & Irritable bowel syndrome & $31 \cdot 8$ & $69 \cdot 4$ \\
\hline 18 & 39 & $\mathbf{M}$ & Irritable bowel syndrome & $24 \cdot 5$ & $63 \cdot 2$ \\
\hline 19 & 35 & $\mathbf{M}$ & Recovering acute pancreatitis & $27 \cdot 5$ & $24 \cdot 5$ \\
\hline 20 & 36 & $\mathbf{M}$ & Irritable bowel syndrome (diarrhoea) & $23 \cdot 8$ & 21.9 \\
\hline 21 & 62 & $\mathrm{~F}$ & Cirrhosis (cryptogenic) & $30 \cdot 2$ & $16 \cdot 2$ \\
\hline 22 & 47 & M & Crohn's disease: intestinal resection & $41 \cdot 5$ & $15 \cdot 1$ \\
\hline 23 & 54 & $\mathrm{M}$ & Duodenal diverticulosis & $26 \cdot 2$ & $16 \cdot 1$ \\
\hline 24 & 47 & $\mathrm{M}$ & Crohn's disease & $27 \cdot \overline{7}$ & $15 \cdot 6$ \\
\hline 25 & 22 & $\mathrm{~F}$ & Thyrotoxicosis: diarrhoea & $26 \cdot 2$ & $17 \cdot 2$ \\
\hline 26 & 23 & $\mathrm{M}$ & Crohn's disease & $33 \cdot 3$ & 6.7 \\
\hline 27 & 25 & $\mathrm{~F}$ & Irritable bowel syndrome (diarrhoea) & $22 \cdot 8$ & $19 \cdot 3$ \\
\hline 28 & 29 & $\mathrm{M}$ & Postvagotomy diarrhoea & $31 \cdot 6$ & 19.9 \\
\hline 29 & 51 & $\mathbf{M}$ & Hepatic fibrosis; spherocytosis & $46 \cdot 7$ & $5 \cdot 8$ \\
\hline 30 & 52 & $\mathrm{M}$ & Generalised arteriosclerosis: CVA & $43 \cdot 3$ & $13 \cdot 5$ \\
\hline 31 & 37 & $\mathrm{~F}$ & Rheumatic heart disease & $24 \cdot 3$ & $17 \cdot 9$ \\
\hline 32 & 45 & $\mathrm{~F}$ & Alcoholic hepatitis & $26 \cdot 4$ & $7 \cdot 2$ \\
\hline 33 & 34 & $\mathrm{~F}$ & Ovarian tumour: hepatic metastases & $22 \cdot 2$ & $6 \cdot \overline{3}$ \\
\hline 34 & 69 & $\mathrm{M}$ & Hepatitis (?alcoholic) & $24 \cdot 1$ & $13 \cdot 0$ \\
\hline 35 & 67 & $\mathrm{~F}$ & Stone in common bile duct & $27 \cdot 5$ & $7 \cdot 7$ \\
\hline 36 & 47 & $\mathrm{M}$ & Coeliac disease (active) & $26 \cdot 0$ & $12 \cdot 2$ \\
\hline 37 & 56 & $\mathbf{M}$ & No organic disease & $31 \cdot 8$ & $9 \cdot 5$ \\
\hline 38 & 44 & $\mathbf{M}$ & Recurring acute pancreatitis & $35 \cdot 4$ & $13 \cdot 3$ \\
\hline 39 & 49 & $\mathrm{M}$ & Cirrhosis (alcoholic) & $57 \cdot 2$ & $17 \cdot 7$ \\
\hline 40 & 41 & $\mathrm{~F}$ & Cholelithiasis & $21 \cdot 0$ & $17 \cdot 6$ \\
\hline 41 & $\begin{array}{l}41 \\
75\end{array}$ & $\mathrm{~F}$ & Cirrhosis (cryptogenic) & $20 \cdot 5$ & $87 \cdot 8$ \\
\hline \multicolumn{4}{|c|}{ Mean $\pm S D$} & $29 \cdot 9 \pm 8 \cdot 7$ & $35 \cdot 2 \pm 26 \cdot 1$ \\
\hline
\end{tabular}

*Normal when corrected for age and weight.

A bicarbonate output of $>20 \mathrm{mmol} / \mathrm{h}$ was considered normal and an output of $<15 \mathrm{mmol} / \mathrm{hwas}$ considered pathological

The fluorescein dilaurate test was considered normal if above $30 \%$ and pathological if below $30 \%$.

Table 2 Patients with abnormal response to secretin and CCK

\begin{tabular}{|c|c|c|c|c|c|}
\hline Case & Age (yr) & Sex & Diagnosis & $\begin{array}{l}\text { Maximal } \\
\text { bicarbonate output } \\
\text { (mmol/h) }\end{array}$ & $\begin{array}{l}\text { Fluorescein excretion } \\
\text { Ccontrol dạ. }\end{array}$ \\
\hline 1 & 16 & $\mathrm{~F}$ & Schwachman's syndrome & $6 \cdot 3$ & $5 \cdot 8$ \\
\hline 2 & 44 & $\mathrm{~F}$ & Chronic pancreatitis (resection) & $14 \cdot 8$ & 3.9 \\
\hline 3 & 50 & $\mathrm{~F}$ & Chronic pancreatitis & 9.9 & $10 \cdot 1$ \\
\hline 4 & 49 & $\mathrm{~F}$ & Pancreatic atrophy & $5 \cdot 7$ & $5 \cdot 2$ \\
\hline 5 & 37 & $\mathbf{M}$ & Chronic pancreatitis & $5 \cdot 4$ & $1 \cdot 5$ \\
\hline 6 & 48 & M & Chronic pancreatitis & $11 \cdot 6$ & $4 \cdot 6$ \\
\hline 7 & 47 & $M$ & Chronic pancreatitis (resection) & $0 \cdot 0$ & $12 \cdot 6$ \\
\hline 8 & 39 & $\mathrm{M}$ & Chronic pancreatitis & $9 \cdot 3$ & $13 \cdot 7$ \\
\hline 9 & 37 & $\mathrm{M}$ & Chronic pancreatitis (resection) & $0 \cdot 0$ & $23 \cdot 0$ \\
\hline 10 & 33 & $\mathrm{M}$ & Chronic pancreatitis & $0 \cdot 0$ & $24 \cdot 7$ \\
\hline 11 & 32 & $\mathbf{M}$ & Chronic pancreatitis & $9 \cdot 0$ & $25 \cdot 9$ \\
\hline 12 & 57 & $\mathrm{~F}$ & Chronic pancreatitis (resection) & $11 \cdot 8$ & $20 \cdot 1$ \\
\hline 13 & 65 & M & Chronic calcific pancreatitis & $10 \cdot 8$ & $8 \cdot 8$ \\
\hline 14 & 72 & $\mathrm{~F}$ & Chronic pancreatitis and cirrhosis & $11 \cdot 2$ & $29 \cdot 5$ \\
\hline Mean & & & & $7 \cdot 6 \pm 4 \cdot 8$ & $13 \cdot 5 \pm 9 \cdot 4$ \\
\hline
\end{tabular}

A bicarbonate output of $>20 \mathrm{mmol} / \mathrm{h}$ was considered normal and an output of $<15 \mathrm{mmol} / \mathrm{h}$ was considered pathological.

The fluorescein dilaurate test was considered normal if above $30 \%$ and pathological if below $30 \%$. 
Table 3 Patients with equivocal response to secretin and CCK

\begin{tabular}{|c|c|c|c|c|c|}
\hline Case & Age (yr) & Sex & Diagnosis & $\begin{array}{l}\text { Maximal } \\
\text { bicarbonate output } \\
\text { (mmolih) }\end{array}$ & $\begin{array}{l}\text { Fluorescein excretion } \\
\text { \% controldan }\end{array}$ \\
\hline 1 & 66 & $\mathrm{~F}$ & Arteriosclerosis mesenteric vascular disease & $17 \cdot 0$ & $8 \cdot 3$ \\
\hline 2 & 18 & $\mathrm{~F}$ & Crohn's disease & $16 \cdot 6$ & $14 \cdot 1$ \\
\hline 3 & 31 & $\mathrm{~F}$ & Ulcerative colitis & $18 \cdot 9$ & $26 \cdot 3$ \\
\hline 4 & 48 & $\mathrm{~F}$ & Recurrent acute pancreatitis & $19 \cdot 0$ & $41 \cdot 3$ \\
\hline 5 & 59 & $\mathrm{~F}$ & Coeliac disease (inactive) & $18 \cdot 3$ & $53 \cdot 8$ \\
\hline \multicolumn{4}{|c|}{ Mean \pm SD } & $18 \cdot 0 \pm 1 \cdot 1$ & $28 \cdot 8 \pm 18 \cdot 9$ \\
\hline
\end{tabular}

A bicarbonate output of $>20 \mathrm{mmol} / \mathrm{h}$ was considered normal and an output of $<15 \mathrm{mmol} / \mathrm{h}$ was considered pathological.

The fluorescein dilaurate test was considered normal if above $30 \%$ and pathological if below $30 \%$.

gastrointestinal motility or secretion were stopped five days before the test.

A $0.5 \mathrm{ml}$ aliquot of urine was mixed with $4.5 \mathrm{ml}$ of 0.1 mol sodium hydroxide and heated to $70^{\circ} \mathrm{C}$ for $10 \mathrm{~min}$ in a water bath. The optical extinction at $492 \mathrm{~nm}$ (lambda max for fluorescein) was compared with water in a spectrophotometer (Pye Unicam SP600) and the excretion of fluorescein

calculated as $\frac{\text { E492 } \times \text { urine vol }}{35}$. The denominator

35 is derived from the dose, dilution and molar extinction coefficient of fluorescein. Excretion on the test day was expressed as a percentage of excretion on the control day. A value of greater than 30 was taken as indicating normal pancreatic exocrine function.

\section{STATISTICAL METHODS}

Sensitivity, specificity and predictive values were expressed using non-Bayesian methods. ${ }^{4}$

Secretin and cholecystokinin were obtained from the GIH Laboratories, Karolinska Institutet, Stockholm.

The fluorescein-dilaurate tests (as "pancreo-lauryl" test) were provided by International Laboratories Ltd. Alton, Hants, England.

Table 4 Result of FDL test

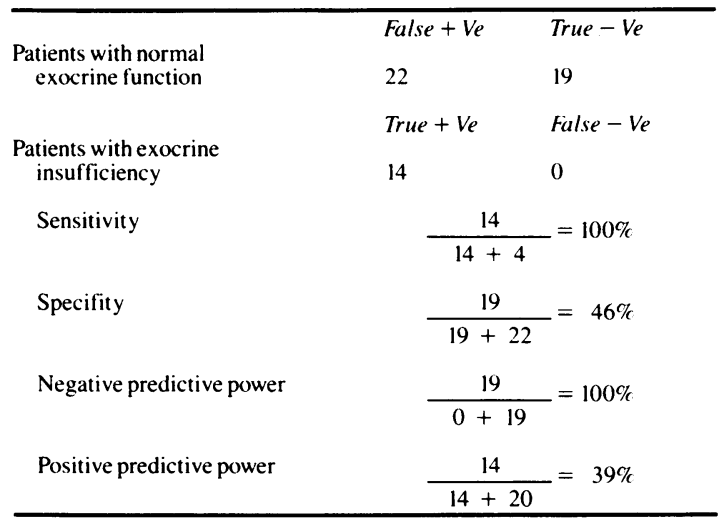

\section{Results}

Forty-one patients had a normal response to secretin and CCK (Table 1), 14 patients had an abnormal response (Table 2) and in five patients the results were equivocal (Table 3). In the patients with unequivocal secretin-CCK tests $(\mathrm{n}=55)$ the fluorescein-dilaurate test had a sensitivity of $100 \%$ and a negative predictive value of $100 \%$ (Table 4 ). There was a $54 \%$ false-positive rate.

The overall relation between the results of the fluorescein-dilaurate test and maximal bicarbonate secretion is depicted in the Figure.

\section{Discussion}

The fluorescein dilaurate test is easy to perform acceptable to patients, has a high sensitivity and negative predictive value, and is therefore likely to be a useful screening test for detecting pancreatic exocrine insufficiency. It seems, on the basis of our results, that a normal fluorescein-dilaurate test makes it highly unlikely that patient has pancreatic insufficiency. In this study approximately half of the patients with normal bicarbonate and enzyme responses to secretin and CCK had normal

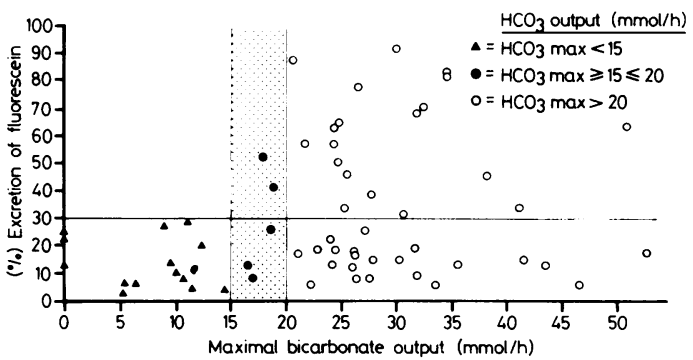

Comparison of \% excretion of fluorescein with bicarbonate secretory capacity.

Each point denotes result from one patient. The three different types of symbol depict patients with respective bicarbonate secretory capacity (see key). The horizontal line shows the lower limit of normal fluorescein excretion.

The hatched vertical column shows range of equivocal bicarbonate outputs. 
fluorescein dilaurate tests and therefore may have been spared intubation. However, in view of the $54 \%$ false-positive rate, it seems that the high sensitivity of the test has been achieved only at the expense of low specificity.

We have used the maximal bicarbonate response to secretin and CCK as the diagnostic criterion for pancreatic exocrine insufficiency, since this criterion provides the best discriminant between patients with and without pancreatic disease. ${ }^{2}$ The use of the maximal enzyme response is less satisfactory, whichever enzyme is used, because there is a considerable overlap in enzyme outputs between patients with and without pancreatic disease.

The fluorescein dilaurate tèst is a test of digestive capacity and is, therefore, dependent on a number of non-pancreatic factors which, if altered, can affect the validity of the test. For example, gastric acid hypersecretion, especially if there is rapid gastric emptying, may flood the duodenum with acid and render pancreatic enzymes inactive, thus giving rise to false-positive results. Since enzymic hydrolysis of fat requires the presence of conjugated bile salts, digestion of the lauryl ester may be impaired in diseases which lower bile-salt concentrations in duodenal contents. In diffuse small intestinal disease, or extensive resection or bypass as a result of disease or surgery, there may be impaired release of endogenous secretin and cholecystokinin with consequently impaired stimulation of pancreatic secretion of enzymes. These factors may have contributed to the large number of patients with false-positive tests five $(20 \%)$ of whom had small intestinal disease and three (15\%) had rapid intestinal transit. Eight of the nine patients with hepatobiliary disease who were studied also had falsepositive tests.

The converse situation - that is, the hydrolysis of the fluorescein dilaurate in the absence of pancreatic aryl esterase, could theoretically give rise to false-negative results. We have not observed any false-negative results with the fluorescein dilaurate test, but we cannot concur with a previous assertion that fluorescein dilaurate is hydrolysed only in the presence of pancreatic aryl esterase since two of our patients (Table 2, cases 9 and 10) who had no enzymic activity in their pancreatic juice achieved excretion ratios of 23 and 24.7 respectively. The mechanism for the hydrolysis of the ester in the absence of pancreatic enzymes has not yet been defined.

Previous reports ${ }^{5.6}$ have attested the value of the fluorescein dilaurate test, with the test giving the correct diagnosis in $93 \%$ and a false-negative rate of $0.1 \%$. The latter studies evaluated the fluorescein-dilaurate test in preselected groups comprising especially patients with known pancreatic disease (often with gross exocrine insufficiency) so that a potentially excessively favourable assessment of diagnostic value was presented. Our study was prospective and in addition to confirming the earlier reports, gives a more accurate assessment of the value of the fluorescein-dilaurate test in clinical practice.

We conclude that the fluorescein-dilaurate test is a useful screening test for pancreatic exocrine insufficiency since its high sensitivity ensures that patients with pancreatic insufficiency are likely to be detected by an abnormal test. The negative predictive value of $100 \%$ means that in patients with a normal test it is usually unnecessary to perform a secretin-CCK test.

We should like to thank Mrs Helen Wood, Mr G Clark and Mr J Dunbar for technical assistance.

The "Pancreo-lauryl" tests were kindly.supplied by $\mathrm{Mr}$ DM Merrington, International Laboratories Ltd. JGRC is supported by the Wellcome Trust. KGW gratefully acknowledges a grant from the Scottish Hospital Endowment Trust.

\section{References}

1 Wormsley KG. Tests of pancreatic secretion. Clin Gastroenterol 1978:7:529-44

2 Wormsley KG. The response to infusion of a combination of secretin and pancreozymin in health and disease. Scand J Gastroenterol 1969:4:623-32

' Kaffarnik H. Meyer-Bertenrath JG. Zur Pankreasspezifität des oralen Funktionstests mit Fluoreszein-di-Monolaurat. Verh Dtsch Ges Imn Med 1971:77:524-6.

${ }^{+}$Galen RS. Gambino SR. Beyond normality: The predictive value and efficiency of medical diagnoses. New York: John Wiley and Sons. 1975.

${ }^{5}$ Kaffarnik H. Klimkeith P. Zöfel P. Otte V. Meyer-Bertenrath JG. Zur klinischen Wertigkeit des oralen Pankreasfunktionstests mit Fluoreszein-Dilaurat. $M M W$ 1977:119:1467-70.

'Lankisch PG. Schreiber A. Koop H. Der Pancreolauryl-Test im Vergleich zum NBT-PABA-Test. Disch Med Wochenschr 1980:43: 1487-8.

Requests for reprints to: Dr KG Wormsley, Ninewells Hospital, Dundee DDI 9SY, Scotland. 